\title{
Resistant Hypertension and Obstructive Sleep Apnea in the Primary-Care Setting
}

\author{
M. Demede, ${ }^{1}$ A. Pandey, ${ }^{1}$ F. Zizi, ${ }^{1,2}$ R. Bachmann, ${ }^{1}$ M. Donat, ${ }^{1,3}$ S. I. McFarlane, ${ }^{4}$ \\ G. Jean-Louis, ${ }^{1,2}$ and G. Ogedegbe ${ }^{5}$ \\ ${ }^{1}$ Brooklyn Center for Health Disparities, Department of Medicine, SUNY Downstate Medical Center, 450 Clarkson Avenue, \\ P.O. Box 1199, Brooklyn, NY 11203-2098, USA \\ ${ }^{2}$ Sleep Disorders Center, Department of Medicine, SUNY Downstate Medical Center, 450 Clarkson Avenue, P.O. Box 1199, \\ Brooklyn, NY 11203-2098, USA \\ ${ }^{3}$ Department of Family Medicine, SUNY Downstate Medical Center, 450 Clarkson Avenue, P.O. Box 1199, Brooklyn, \\ NY 11203-2098, USA \\ ${ }^{4}$ Department of Endocrinology, SUNY Downstate Medical Center, 450 Clarkson Avenue, P.O. Box 1199, Brooklyn, \\ NY 11203-2098, USA \\ ${ }^{5}$ Center for Healthful Behavior Change, Division of Internal Medicine, NYU Medical Center, New York, NY 10016, USA
}

Correspondence should be addressed to G. Jean-Louis, gjean-louis@downstate.edu

Received 14 February 2011; Accepted 28 March 2011

Academic Editor: Adam T. Whaley-Connell

Copyright (C 2011 M. Demede et al. This is an open access article distributed under the Creative Commons Attribution License, which permits unrestricted use, distribution, and reproduction in any medium, provided the original work is properly cited.

\begin{abstract}
We ascertained the prevalence of resistant hypertension (RH) among blacks and determined whether RH patients are at greater risk for obstructive sleep apnea (OSA) than hypertensives. Method. Data emanated from Metabolic Syndrome Outcome Study (MetSO), a study investigating metabolic syndrome among blacks in the primary-care setting. Sample of 200 patients (mean age $=63 \pm 13$ years; female $=61 \%$ ) with a diagnosis of hypertension provided subjective and clinical data. RH was defined using the JNC 7and European Society guidelines. We assessed OSA risk using the Apnea Risk Evaluation System ARES), defining high risk as a total ARES score $\geq 6$. Results. Overall, $26 \%$ met criteria for RH and $40 \%$ were at high OSA risk. Logistic regression analysis, adjusting for effects of age, gender, and medical co morbidities, showed that patients with RH were nearly 2.5 times more likely to be at high OSA risk, relative to those with hypertension ( $\mathrm{OR}=2.46,95 \% \mathrm{CI}: 1.03-5.88, P<.05)$. Conclusion. Our findings show that the prevalence of RH among blacks fell within the range of RH for the general hypertensive population (3-29\%). However, patients with $\mathrm{RH}$ were at significantly greater risk of OSA compared to patients with hypertension.
\end{abstract}

\section{Introduction}

Resistant hypertension (RH) is defined as blood pressure that remains above goal $(<140 / 90)$ in spite of concurrent use of three antihypertensive agents of different classes, one of which being a diuretic; all agents should be prescribed at optimal dosage amounts. Furthermore, observed blood pressure (BP) requiring $\geq 4$ medications to reach controlled $\mathrm{BP}$ should be considered resistant to treatment $[1,2]$.

Longitudinal studies and clinical trials have shown that $\mathrm{RH}$ is a common public health problem. Data from the ALLHAT trial indicated that the prevalence of resistant hypertension is $27 \%$ [3]. The Outpatient Quality Improvement Network's Hypertension Initiative, sampling primarycare clinics in South Carolina, North Carolina, and Georgia ( $n=264,967$ hypertensive patients), estimated that the overall prevalence of $\mathrm{RH}$ is about $16 \%$ [4]. Of note, $50 \%$ of the participants in both the National Health and Nutrition Examination Survey (NHANES) [5] and Framingham Heart Study [6] were able to reach a therapeutic goal of $<140 / 90 \mathrm{mmHg}$. Those comprising the group who failed to reach the therapeutic goal likely included resistant hypertensives and pseudoresistant hypertensives. Given the increased trends in metabolic syndrome and obstructive sleep apnea 
(OSA), RH management will constitute a daunting task, with important social and economic ramifications. The special risk group is more likely to have target-organ damage and a higher long-term cardiovascular risk than resistant hypertension patients with controlled hypertension.

Great strides have been made in establishing obstructive sleep apnea as a target of therapy among hypertensives [7-9]. This is consistent with results of several multivariate analytical models indicating that OSA represents an independent risk factor for hypertension [10-12], and hypertension constitutes a significant predictor of cardiovascular deaths among patients with OSA [12]. The prevalence of resistant hypertension itself among men with a diagnosis of OSA may be as high as $85 \%(83 \%(n=42$; AHI $\geq 10 / \mathrm{h})$ [13] and $n=29$; AHI $\geq 5 /$ h) [14].

No epidemiologic or clinical study has investigated OSA risk among minority patients with RH. It is evident, however, that blacks exhibit greater resistance to treatment [15] and black women have the highest prevalence of hypertension [16] and the lowest blood pressure control [3]. Evidence also shows that hypertensive blacks with a family history of hypertension are likely to have higher baseline blood pressure, and a greater number of oxygen desaturations and apnea hypoapnea index than their white counterparts [17]. This study ascertained the prevalence of $\mathrm{RH}$ among black patients in the primary-care setting. It also determined whether patients with $\mathrm{RH}$ are at greater risk for obstructive sleep apnea (OSA) than hypertensives.

\section{Method}

2.1. Sample. Data $(n=200$, mean age $=63 \pm 13$ years; female $=61 \%)$ emanated from the Metabolic Syndrome Outcome Study (MetSO). This is an NHLBI-funded study investigating effects of OSA treatment among blacks in the primarycare setting. Data were obtained from four clinics associated with SUNY Downstate Medical Center including, Family Medicine Clinic, Heart Failure Clinic, Diabetes Clinic, and Lefferts Community Health Center.

2.2. Procedures. Study staff approached patients in the primary-care settings to solicit their participation. Those agreeing to participate provided informed consent and filled out a brief questionnaire on sleep problems, medical history, and use of medications. They also provided responses to the Apnea Risk Evaluation System (ARES) Questionnaire [18]. The Apnea Risk Evaluation System (ARES) Questionnaire was used to identify those at high sleep apnea risk. This system is recommended in situations where the population has a large pretest probability. The questionnaire solicits demographic and anthropometric data, diseases associated with risk for sleep apnea (i.e., HTN, DM, heart disease, or stroke), or prior diagnosis of sleep apnea, the Epworth Sleepiness Scale, and frequency rating for snoring, waking up choking, and having been told that patients stopped breathing during sleep. Validation study showed that ARES has a sensitivity of 0.94 , specificity of 0.79 (based on a clinical cut-off of AHI >5), positive predictive value of 0.91 , and negative predictive value of 0.86 [19].
Clinical data including body mass index (BMI), blood pressure, high-density lipoprotein cholesterol (HDLC), and fasting plasma glucose (FPG) or hemoglobin (HbAlc) for those who have a diagnosis of diabetes were obtained from the MetSO registry [20-22]. RH was defined using the JNC 7 and European Society guidelines (uncontrolled BP despite treatment with 3 medications or controlled BP with 4 or more medications, including a diuretic, in suitable combination and recommended dosage). Uncontrolled HTN is defined as average systolic and diastolic BP $>140 / 90 \mathrm{~mm} / \mathrm{Hg}$ (for those without comorbidity), or average clinic SBP $>130 \mathrm{~mm} / \mathrm{Hg}$ or DBP $>80 \mathrm{~mm} / \mathrm{Hg}$ (for those with diabetes or kidney disease).

2.3. Statistical Analysis. Frequency and measures of central tendency were used to describe the sample. In preliminary analyses, Pearson and Spearman correlations were used to explore relationships between variables of interest. To test the hypothesis that patients with $\mathrm{RH}$ were more likely to be at high OSA risk, compared with those with hypertension, we utilized multivariate logistic regression modeling. Covariates entered in the model were age, sex, obesity (defined as BMI $\geq 30 \mathrm{~kg} / \mathrm{m}^{2}$ ), a history of diabetes, dyslipidemia, heart disease, and depression. Before constructing the model, correlational analyses were performed to assess associations between hypothesized predictors and the dependent variable. All analyses were performed using SPSS (version 18.0; SPSS Inc. Chicago).

\section{Results}

Of the sample, $68 \%$ were diagnosed with diabetes, $83 \%$ dyslipidemia, and 38\% heart disease; $89 \%$ were overweight/obese. Average systolic and diastolic BP were 135 $\pm 19 \mathrm{mmHg}$ and $75 \pm 11 \mathrm{mmHg}$, respectively. Blood glucose levels averaged $145 \pm 64 \mathrm{mg} / \mathrm{dL}$, triglycerides $147 \pm$ $85 \mathrm{mg} / \mathrm{dL}$, and LDL $97 \pm 38 \mathrm{mg} / \mathrm{dL}$. Overall, $26 \%$ met criteria for $\mathrm{RH}$ and $40 \%$ were at high OSA risk.

Multivariate logistic regression analysis, adjusting for effects of age, gender, and medical comorbidities, showed that patients with RH were nearly 2.5 times more likely to be at high OSA risk, relative to those with hypertension $(\mathrm{OR}=$ 2.46, 95\% CI: 1.03-5.88, $P<.05)$. Univariate results for each of the factors entered in the model are indicated in Table 1.

\section{Discussion}

Several factors may be liable for low OSA screening rates in the general population [23-25]. Evidence shows that healthcare providers do not commonly screen for OSA among patients with metabolic dysfunctions [26]. This is compounded by the fact that patients are usually unaware of the nature and significance of sleep apnea and its association with hypertension [27]. Yet, yearly hypertension contributes to $14 \%$ of deaths occurring in the United States, and to nearly half of all cardiovascular disease-related deaths [28]. From 1997 to 2007, the death rate caused by high blood pressure increased to $9.0 \%$, and the actual number of deaths rose $35.6 \%$ [29]. If all hypertensive patients were treated 
adequately to reach the goal specified in current clinical guidelines, 46,000 deaths might be averted annually [30].

The first finding of our study is that the prevalence of resistant hypertension among blacks is $26 \%$. This point estimate falls within the range of $\mathrm{RH}$ for the general hypertensive population (3-29\%), albeit towards the high end. Our study confirms previous clinical studies, which have tended to include smaller sample sizes $(n<50)[13,14]$. No comparisons could be made with other racial/ethnic groups, as data from such groups were not available. Notwithstanding this limitation, the study provides useful data for black hypertensives that may provide a basis for comparison with other populations in future studies. To our knowledge, previous studies provided no specific estimates for patients of the black race/ethnicity.

The second finding of our study is that patients with RH were nearly 2.5 times more likely to be at high OSA risk, relative to those with hypertension. Of note, this finding was independent of patients' demographic factors and RHassociated medical conditions. This evidence suggests that greater effort should be made to screen individuals with resistant hypertension for the presence of OSA. Consistent with evidence that OSA treatment has significant positive effects in reducing cardiovascular disease risk [31], $\mathrm{RH}$ patients at high risk for OSA should be the target of aggressive therapeutic management. Evidence suggests that treatment of OSA among RH patients may facilitate achievement of optimal BP control.

Findings of this study demonstrate that both sleep apnea and resistant hypertension represent major public health concerns among black patients [32]. This is a serious concern since few blacks (38\%) adhered to physician-recommended OSA assessment [33]. OSA is underdiagnosed because of lack of awareness among blacks or health professionals [34-38]. There is evidence suggesting that although the frequency of snoring, the main OSA symptom, is higher among blacks, they are less likely than whites to report it $[39,40] ; 33 \%$ of blacks considered snoring to be normal, relative to $20 \%$ of whites. The observation that blacks with these medical conditions are often nonadherent to prescribed medical treatments [41-43] renders clinical management even more complicated.

The benefits of CPAP treatment have been convincingly demonstrated among individuals with a dual diagnosis of hypertension and OSA. Emerging evidence has shown that long-term adherence to continuous positive airway pressure (CPAP) therapy suppressd sympathetic activity and improved blood pressure among patients with $\mathrm{RH}$ as well. Multiple studies have shown significant net reduction in blood pressure among RH patients who received CPAP treatment [44-46]. In a recent randomized clinical trial comparing effects of CPAP treatment with conventional treatment, investigators showed a decrease in 24-hour diastolic BP $(-4.9 \pm 6.4$ versus. $0.1 \pm 7.3 \mathrm{mmHg}, P=.027)$ among patients with resistant hypertension. Furthermore, congruent with current evidence, patients using CPAP for 5.8 hours or longer showed a greater reduction in daytime diastolic BP, 24-hour diastolic BP, and 24-hour systolic BP [47]. It is important to conduct randomized CPAP clinical
TABLE 1: Regression coefficients of the OSA risk factor on resistant hypertension relative to hypertension, sociodemographic factors, and medical factors; ${ }^{*} P<.05$.

\begin{tabular}{lcc}
\hline $\begin{array}{l}\text { Associations of resistant hypertension and sociodemographic } \\
\text { and medical factors with OSA risk }\end{array}$ & OR & $95 \%$ C.I. \\
Variables & 2.46 & $1.03-$ \\
Resistant hypertension & .98 & $.988^{*}$ \\
Age & .65 & $.30-1.01$ \\
Sex & 2.29 & $.58-9.05$ \\
Body mass index & 1.02 & $.35-2.98$ \\
Dyslipidemia & 2.29 & $.95-5.57$ \\
Diabetes & .99 & $.99-1.02$ \\
Heart disease & .93 & $.20-4.48$ \\
Depression & & \\
\hline
\end{tabular}

trials among high-risk racial/ethnic minorities, especially blacks, to assess whether CPAP therapy has similar long-term effects.

\section{Acknowledgment}

This paper was supported by funding from the NIH (R25HL105444, R01MD004113, and P20MD005092).

\section{References}

[1] D. A. Calhoun, D. Jones, S. Textor, D. C. Goff, T. P. Murphy, and R. D. Toto, "Resistant hypertension: diagnosis, evaluation, and treatment: a scientific statement from the American Heart Association Professional Education Committee of the Council for High Blood Pressure Research," Circulation, vol. 117, no. 25, pp. e510-e526, 2008.

[2] D. A. Calhoun, D. Jones, S. Textor, D. C. Goff, T. P. Murphy, and R. D. Toto, "Resistant hypertension: siagnosis, evaluation, and treatment a scientific statement from the american heart association professional education committee of the council for high blood pressure research," Hypertension, vol. 51, no. 6, pp. 1403-1419, 2008.

[3] W. C. Cushman, C. E. Ford, J. A. Cutler, K. L. Margolis, B. R. Davis, and R. H. Grimm, "Success and predictors of blood pressure control in diverse North American settings: the antihypertensive and lipid-lowering treatment to prevent heart attact trial (ALLHAT)," Journal of Clinical Hypertension, vol. 4, no. 6, pp. 393-404, 2002.

[4] B. M. Egan, D. T. Lackland, and J. N. Basile, "American Society of Hypertension regional chapters: leveraging the impact of the Clinical Hypertension Specialist in the local community," American Journal of Hypertension, vol. 15, no. 4 I, pp. 372-379, 2002.

[5] I. Hajjar and T. A. Kotchen, "Trends in prevalence, awareness, treatment, and control of hypertension in the United States, 1988-2000," Journal of the American Medical Association, vol. 290, no. 2, pp. 199-206, 2003.

[6] D. M. Lloyd-Jones, J. C. Evans, M. G. Larson, C. J. O’Donnell, E. J. Roccella, and D. Levy, "Differential control of systolic and diastolic blood pressure factors associated with lack of blood pressure control in the community," Hypertension, vol. 36, no. 4, pp. 594-599, 2000. 
[7] F. Siyam, S. A. Brietzke, and J. R. Sowers, "Resistant hypertension in office practice: a clinical approach," Hospital Practice, vol. 38, no. 4, pp. 90-97, 2010.

[8] A. V. Chobanian, G. L. Bakris, H. R. Black et al., "The seventh report of the joint national committee on prevention, detection, evaluation, and treatment of high blood pressure: The JNC 7 Report," Journal of the American Medical Association, vol. 289, no. 19, pp. 2560-2572, 2003.

[9] V. K. Somers, D. P. White, R. Amin et al., "Sleep apnea and cardiovascular disease. An American Heart Association/American College of Cardiology Foundation Scientific Statement from the American Heart Association Council for high blood pressure research professional education committee, Council on Clinical Cardiology, Stroke Council, and Council on Cardiovascular Nursing in Collaboration with the National Heart, Lung," Journal of the American College of Cardiology, vol. 52, no. 8, pp. 686-717, 2008.

[10] M. M. Ohayon, C. Guilleminault, R. G. Priest, J. Zulley, and S. Smirne, "Is sleep-disordered breathing an independent risk factor for hypertension in the general population $(13,057$ subjects)?" Journal of Psychosomatic Research, vol. 48, no. 6, pp. 593-601, 2000.

[11] T. Young, P. Peppard, M. Palta et al., "Population-based study of sleep-disordered breathing as a risk factor for hypertension," Archives of Internal Medicine, vol. 157, no. 15, pp. 1746-1752, 1997.

[12] P. Lavie, P. Herer, and V. Hoffstein, "Obstructive sleep apnoea syndrome as a risk factor for hypertension: population study," British Medical Journal, vol. 320, no. 7233, pp. 479-482, 2000.

[13] A. G. Logan, S. M. Perlikowski, A. Mente et al., "High prevalence of unrecognized sleep apnoea in drug-resistant hypertension," Journal of Hypertension, vol. 19, no. 12, pp. 2271-2277, 2001.

[14] M. N. Pratt-Ubunama, M. K. Nishizaka, R. L. Boedefeld, S. S. Cofield, S. M. Harding, and D. A. Calhoun, "Plasma aldosterone is related to severity of obstructive sleep apnea in subjects with resistant hypertension," Chest, vol. 131, no. 2, pp. 453-459, 2007.

[15] W. C. Cushman, C. E. Ford, P. T. Einhorn et al., "Blood pressure control by drug group in the antihypertensive and lipid-lowering treatment to prevent heart attack trial (ALLHAT)," Journal of Clinical Hypertension, vol. 10, no. 10, pp. 751-760, 2008.

[16] V. L. Roger, A. S. Go, D. M. Lloyd-Jones, R. J. Adams, J. D. Berry, and T. M. Brown, "Heart disease and stroke statistics2011 Update. A Report from the American Heart Association," Circulation, vol. 123, no. 4, pp. e18-e209, 2011.

[17] G. Jean-Louis, F. Zizi, G. Casimir, J. DiPalma, and R. Mukherji, "Sleep-disordered breathing and hypertension among African Americans," Journal of Human Hypertension, vol. 19, no. 6, pp. 485-490, 2005.

[18] D. J. Levendowski, T. Morgan, J. Montague, V. Melzer, C. Berka, and P. R. Westbrook, "Prevalence of probable obstructive sleep apnea risk and severity in a population of dental patients," Sleep and Breathing, vol. 12, no. 4, pp. 303309, 2008.

[19] D. J. Levendowski, E. M. Olmstead, D. Popovich, D. Carper, C. Berka, and P. R. Westbrook, "Assessment of obstructive sleep apnea risk and severity in truck drivers: validation of a screening questionnaire," Sleep Diagnosis and Therapy, vol. 2, no. 2, pp. 20-26, 2007.

[20] E. S. Ford, "Prevalence of the metabolic syndrome defined by the international diabetes federation among adults in the U.S," Diabetes Care, vol. 28, no. 11, pp. 2745-2749, 2005.
[21] T. G. Pickering, J. E. Hall, L. J. Appel et al., "Recommendations for blood pressure measurement in humans and experimental animals_-part 1: blood pressure measurement in humansa statement for professionals from the Subcommittee of Professional and Public Education of the American Heart Association Council on high blood pressure research," Circulation, vol. 111, no. 5, pp. 697-716, 2005.

[22] L. Kennedy and W. H. Herman, "Glycated hemoglobin assessment in clinical practice: comparison of the A1cNow point-of-care device with central laboratory testing (GOAL A1C study)," Diabetes Technology and Therapeutics, vol. 7, no. 6, pp. 907-912, 2005.

[23] S. A. Chung, S. Jairam, M. R. G. Hussain, and C. M. Shapiro, "How, what, and why of sleep apnea. Perspectives for primary care physicians," Canadian Family Physician, vol. 48, pp. 10731080, 2002.

[24] T. Young, L. Evans, L. Finn, and M. Palta, "Estimation of the clinically diagnosed proportion of sleep apnea syndrome in middle-aged men and women," Sleep, vol. 20, no. 9, pp. 705706, 1997.

[25] S. K. Ramachandran and L. A. Josephs, "A meta-analysis of clinical screening tests for obstructive sleep apnea," Anesthesiology, vol. 110, no. 4, pp. 928-939, 2009.

[26] A. C. Elliott, "Primary care assessment and management of sleep disorders," Journal of the American Academy of Nurse Practitioners, vol. 13, no. 9, pp. 409-418, 2001.

[27] M. R. Jonovich and J. D. Bisognano, "Management of hypertension in chronic heart failure," 2009.

[28] T. A. Farley, M. A. Dalal, F. Mostashari, and T. R. Frieden, "Deaths preventable in the U.S. by improvements in use of clinical preventive services," American Journal of Preventive Medicine, vol. 38, no. 6, pp. 600-609, 2010.

[29] J. Q. Xu, K. D. Kochanek, and B. Tejada-Vera, "Deaths: final data for 2007," National Vital Statistics Reports, vol. 58, no. 19, 2010.

[30] M. D. Drennan, D. F. Kripke, H. A. Klemfuss, and J. D. Moore, "Potassium affects actigraph-identified sleep," Sleep, vol. 15, no. 5, pp. 430-433, 1992.

[31] N. J. Buchner, B. M. Sanner, J. Borgel, and L. C. Rump, "Continuous positive airway pressure treatment of mild to moderate obstructive sleep apnea reduces cardiovascular risk," American Journal of Respiratory and Critical Care Medicine, vol. 176, no. 12, pp. 1274-1280, 2007.

[32] S. Redline, P. V. Tishler, M. G. Hans, T. D. Tosteson, K. P. Strohl, and K. Spry, "Racial differences in sleep-disordered breathing in African-Americans and Caucasians," American Journal of Respiratory and Critical Care Medicine, vol. 155, no. 1, pp. 186-192, 1997.

[33] G. Jean-Louis, H. von Gizycki, F. Zizi, A. Dharawat, J. M. Lazar, and C. D. Brown, "Evaluation of sleep apnea in a sample of black patients," Journal of Clinical Sleep Medicine, vol. 4, no. 5, pp. 421-425, 2008.

[34] E. M. Ball, R. D. Simon Jr., A. A. Tall, M. B. Banks, G. NinoMurcia, and W. C. Dement, "Diagnosis and treatment of sleep apnea within the community: the Walla Walla project," Archives of Internal Medicine, vol. 157, no. 4, pp. 419-424, 1997.

[35] A. Bahammam and M. Kryger, "Decision making in obstructive sleep-disordered breathing: putting it all together," Otolaryngologic Clinics of North America, vol. 32, no. 2, pp. 333$348,1999$. 
[36] S. A. Chung, S. Jairam, M. R. G. Hussain, and C. M. Shapiro, "Knowledge of sleep apnea in a sample grouping of primary care physicians," Sleep and Breathing, vol. 5, no. 3, pp. 115121, 2001.

[37] D. S. Silverberg, A. Oksenberg, and A. Iaina, "Sleep related breathing disorders are common contributing factors to the production of essential hypertension but are neglected, underdiagnosed, and undertreated," American Journal of Hypertension, vol. 10, no. 12 I, pp. 1319-1325, 1997.

[38] "The National Commission on Sleep Disorders Research," 2011.

[39] M. Friedman, D. Bliznikas, M. Klein, P. Duggal, M. Somenek, and N. J. Joseph, "Comparison of the incidences of obstructive sleep apnea-hypopnea syndrome in African-Americans versus Caucasian-Americans," Otolaryngology, vol. 134, no. 4, pp. 545-550, 2006.

[40] G. T. O'Connor, B. K. Lind, E. T. Lee et al., "Variation in symptoms of sleep-disordered breathing with race and ethnicity: the Sleep Heart Health Study," Sleep, vol. 26, no. 1, pp. 74-79, 2003.

[41] L. K. Williams, C. L. Joseph, E. L. Peterson et al., "Raceethnicity, crime, and other factors associated with adherence to inhaled corticosteroids," Journal of Allergy and Clinical Immunology, vol. 119, no. 1, pp. 168-175, 2007.

[42] B. J. Turner, C. Hollenbeak, M. G. Weiner, T. Ten Have, and C. Roberts, "Barriers to adherence and hypertension control in a racially diverse representative sample of elderly primary care patients," Pharmacoepidemiology and Drug Safety, vol. 18, no. 8, pp. 672-681, 2009.

[43] C. D. Ndumele, S. Shaykevich, D. Williams, and L. S. Hicks, "Disparities in adherence to hypertensive care in urban ambulatory settings," Journal of Health Care for the Poor and Underserved, vol. 21, no. 1, pp. 132-143, 2010.

[44] A. G. Logan, R. Tkacova, S. M. Perlikowski et al., "Refractory hypertension and sleep apnoea: effect of CPAP on blood pressure and baroreflex," European Respiratory Journal, vol. 21, no. 2, pp. 241-247, 2003.

[45] M. A. Martínez-García, R. Gómez-Aldaraví, J. J. SolerCataluña, T. G. Martínez, B. Bernácer-Alpera, and P. RománSánchez, "Positive effect of CPAP treatment on the control of difficult-to-treat hypertension," European Respiratory Journal, vol. 29, no. 5, pp. 951-957, 2007.

[46] T. A. Dernaika, G. T. Kinasewitz, and M. M. Tawk, "Effects of nocturnal continuous positive airway pressure therapy in patients with resistant hypertension and obstructive sleep apnea," Journal of Clinical Sleep Medicine, vol. 5, no. 2, pp. 103107, 2009.

[47] L. Lozano, J. L. Tovar, G. Sampol et al., "Continuous positive airway pressure treatment in sleep apnea patients with resistant hypertension: a randomized, controlled trial," Journal of Hypertension, vol. 28, no. 10, pp. 2161-2168, 2010. 


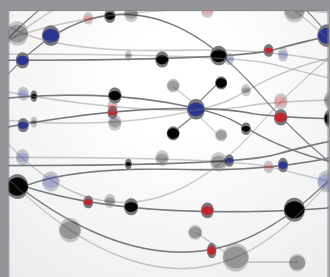

The Scientific World Journal
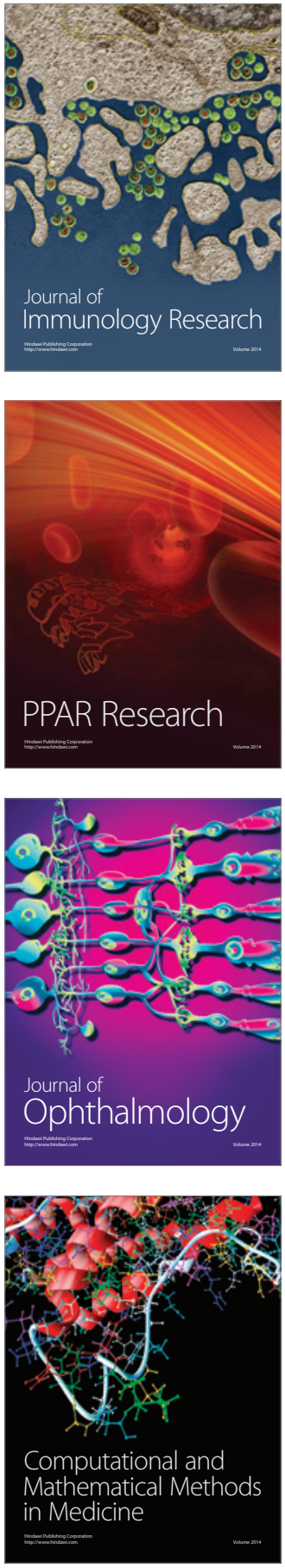

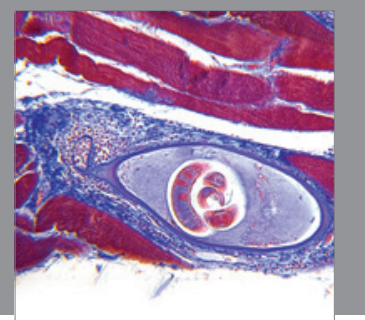

Gastroenterology

Research and Practice
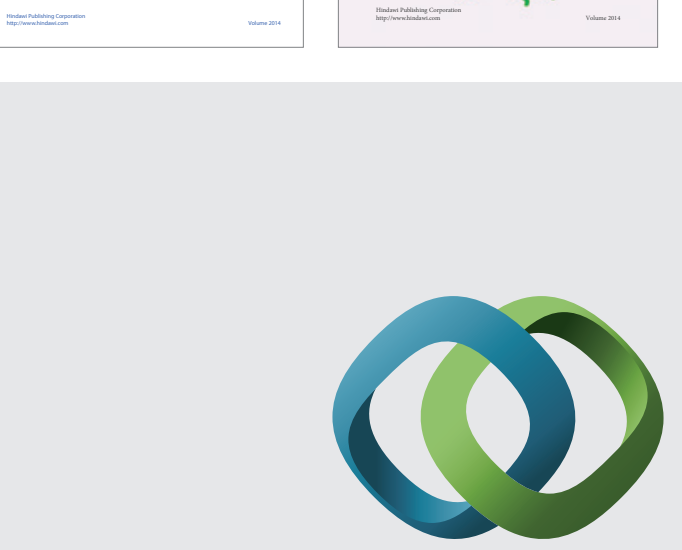

\section{Hindawi}

Submit your manuscripts at

http://www.hindawi.com
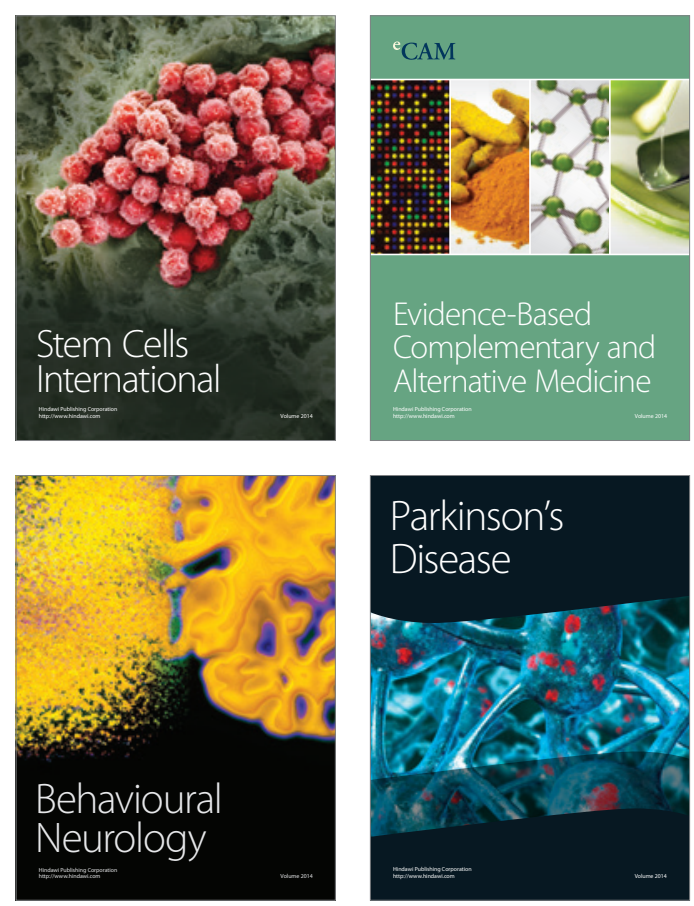

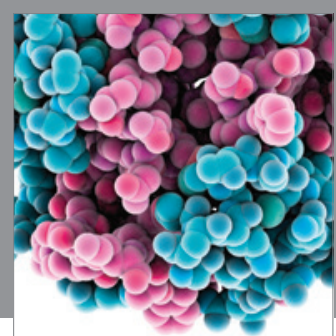

Journal of
Diabetes Research

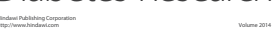

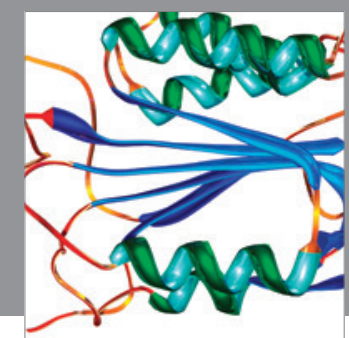

Disease Markers
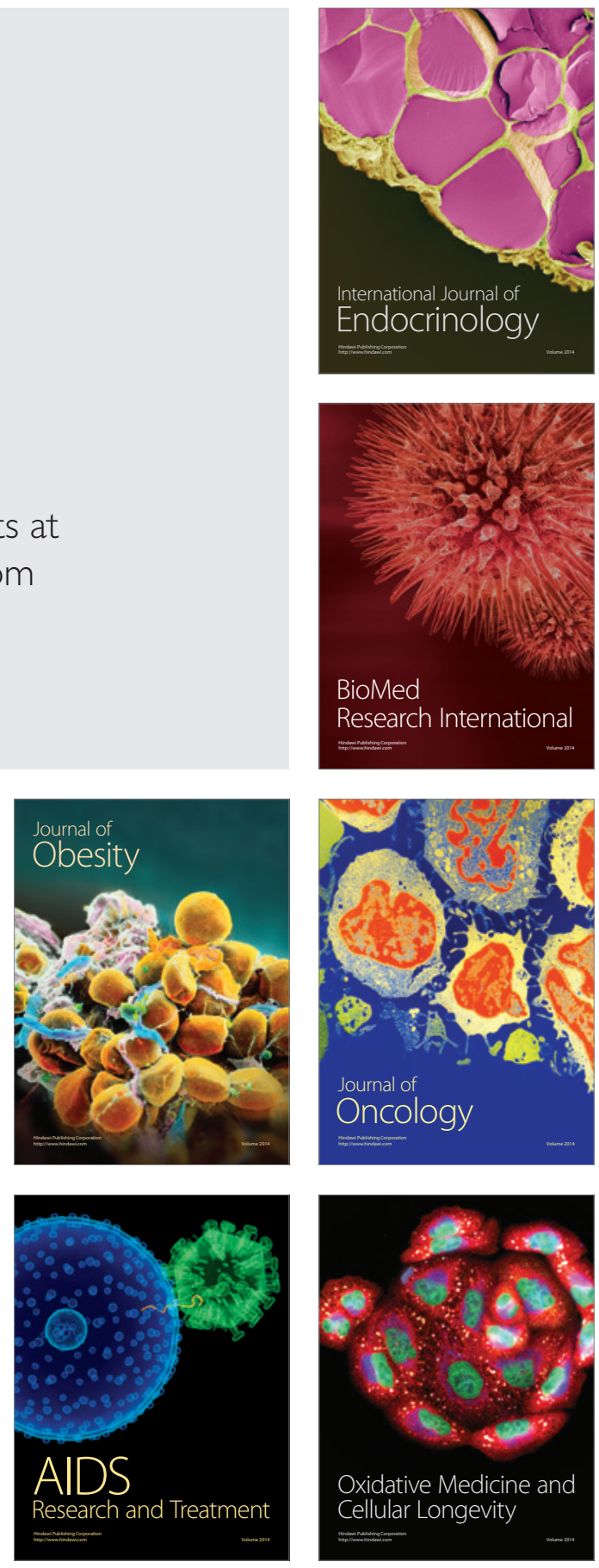